\title{
The transtheoretical model (TTM) questionnaire for smoking cessation: psychometric properties of the Iranian version
}

\author{
Fatemeh Sarbandi ${ }^{1}$, Shamsaddin Niknami ${ }^{*}$, Alireza Hidarnia ${ }^{1}$, Ebrahim Hajizadeh ${ }^{2}$ and Ali Montazeri $^{3}$
}

\begin{abstract}
Background: The transtheoretical model (TTM) is a common framework for studies of smoking cessation. Using the TTM, several instruments were developed to measure to what extent interventions could make changes in people's behavior. The current study aimed to test the validity and reliability of the Persian version of a TTM based questionnaire for smoking cessation in Iran.

Methods: This was a cross-sectional validation study among adult male smokers using the TTM Questionnaire. Backward-forward procedure was applied to translate the questionnaire from English into Persian (the Iranian language). The confirmatory factor analyses were performed to test validity. The internal consistency and stability of the questionnaire was examined using Cronbach's alpha coefficient and Intraclass Correlation Coefficient (ICC).

Results: In all 150 male smokers were entered into the study. The mean age of participants was $36.51 \pm 7.94$ years. The results obtained from confirmatory factor analysis revealed that the data was fit to the model: the goodness of fit index $(\mathrm{GFI})=0.92$; the comparative fit index $(\mathrm{CFI})=0.91$; the root mean square error of approximation $(\mathrm{RMSEA})=$ $0.065(95 \% \mathrm{Cl}=0.063-0.067)$, and the relative chi-square $\left(\mathrm{x}^{2} / \mathrm{df}\right)=1.87, \mathrm{p}<0.001$. The Cronbach's alpha ranged from 0.60 to 0.84 indicating an acceptable result. Also Intraclass Correlation of Coefficient (ICC) ranged from 0.61 to 0.83 corresponding to a satisfactory finding.

Conclusion: The current study provided psychometric evidence for an appropriate, reliable, and valid tool to determine smoking behaviors among Iranian adult smokers. Indeed the findings from this study could be applied in designing smoking cessation interventions in Iran.
\end{abstract}

\section{Background}

Successful strategies implementing smoking cessation are account for cardinal investments in tobacco control programs [1]. Such strategies are theory driven and usually are based on various models of behavioral change. One of the models that have been utilized in smoking cessation is the transtheoreticlal model (TTM). The TTM emerged from more than 300 theories of psychotherapy and behavior change that has been validated and popularized by Prochaska and colleagues since over last 20 years [2]. The TTM consists of four constructs namely: stage of change, processes of change, decisional balance, and temptation [2-4]. In fact this model offers a framework that assumes

\footnotetext{
*Correspondence: niknamis@modares.ac.ir

'Department of Health Education, Faculty of Medical Sciences, Tarbiat Modares University, Jalal Ale Ahmad Highway, P.O. Box: 14115-331, Tehran, Iran

Full list of author information is available at the end of the article
}

health behavior change involves progress through five stages of change, ten processes of change, two decisional balance and three temptation domains as summarized in Figure 1.

Using the TTM several instruments were developed to measure to what extent interventions could make changes in people's behavior. For instance there are instruments that measure life style changes such as physical activity, nutrition, weight loss, and smoking [4-9]. In western countries the English version of the TTM Questionnaire(s) have been validated in many investigations [9-12], but unfortunately in developing countries the literature on the topic is limited. An instrument that describes health behavior or health behavior changes can be used in different cultures and ethnic backgrounds if ensuring that essential linguistic adaptation was applied. In fact culturally and linguistically competent questionnaires take into account cultural values,

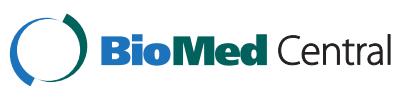




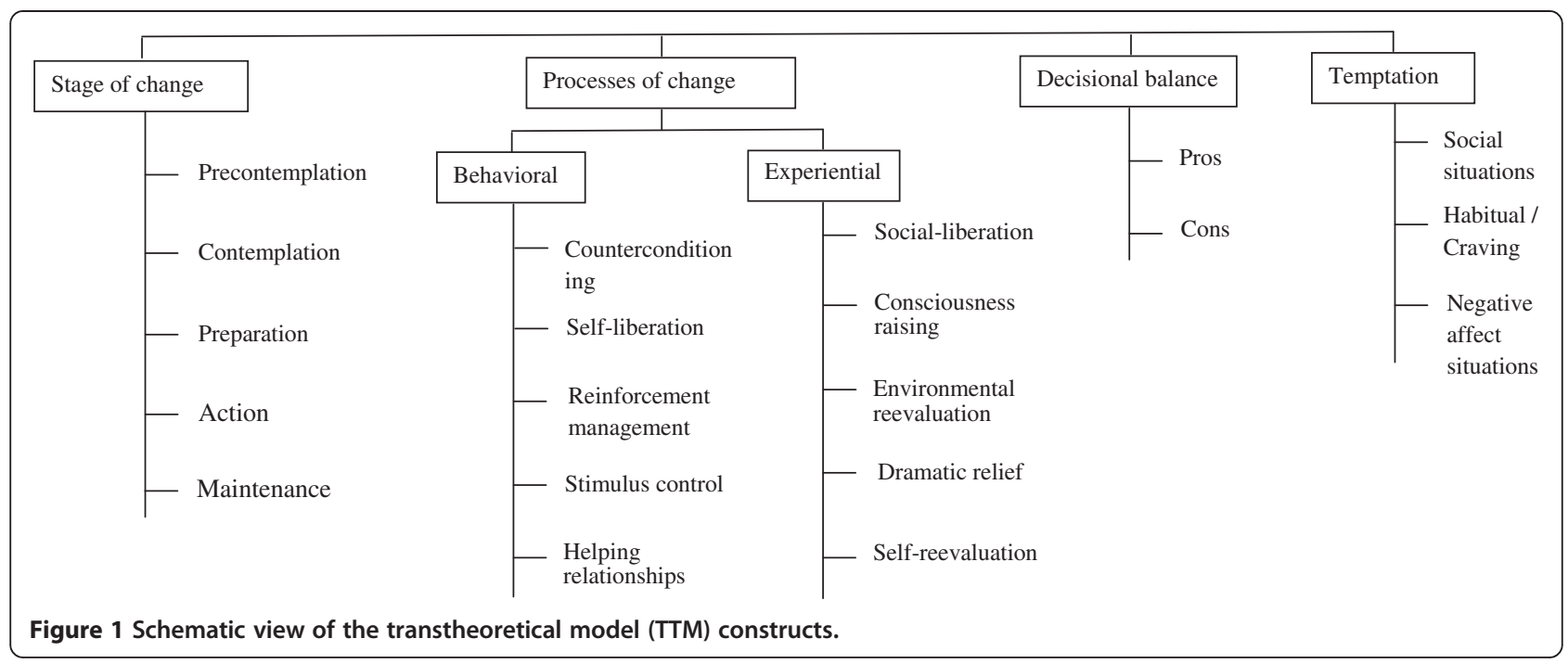

beliefs and practices that might differ among different populations. Therefore, it is necessary to re-examine the validity and reliability of such measures in any given culture. Hence, the aim of this research was to test the validity and reliability of the Persian version of TTM Questionnaire for smoking cessation in Iran in order to provide a theorybased instrument for measuring behavior changes following public health interventions.

\section{Methods}

\section{Participants and procedures}

This was a cross-sectional validation study conducted between November and December 2012. Participants were recruited from 6 factories in Tehran, Iran. Inclusions criteria were; being male, current smoker with history of smoking at least 100 cigarettes, not involved in any quit attempt, planning on quitting smoking in the next 30 days, and being able to read and write in Persian. The main reason for including only one group (people in the preparation stage) was due to the fact that we were planning to implement an intervention for these people. Since according to the TTM, every stage of change needs its own strategy for any possible interventions [2]; we thought the most convenient sample for the study would be a sample of individuals who are at preparation stage; otherwise we should have been implemented a number of different interventions for people in different stages of change and this was impossible for several reasons including time constrains and scarce resources. However, the study questionnaire was distributed to the participants at worksite settings over a period of two weeks.

\section{The TTM questionnaire}

The TTM Questionnaire for smoking cessation was developed by Prochaska and colleagues [12,13] and it is available in two versions: the original questionnaire containing
83 items and the short form containing 38 items. In the current study we used the short form. Both versions include 4 constructs:

a. The stage of change: that assesses the current conditions of individuals' smoking habits and whether they wish to quit smoking or not. In theory there are five stages and an individual could indicate that he or she is at one of these stages that are: precontemplation, contemplation, preparation, action and maintenance. For instance first it distinguishes current smoker, ex-smoker and nonsmoker. Then current smokers answer two questions: history of quit smoking and cessation stage of smoking. In this study if a participant was planning to quit smoking within the next 30 days and had made a quit attempt in the past year he was identified as being in preparation stage. The stage of change is a dependent variable and does not incorporate into the model $[9-11,14]$.

b. The processes of change: it measures ten processes of change under two main categories: experiential and behavioral activities to change their smoking behavior. It includes 10 statements about experiential and 10 statements about behavioral processes. Examples of items for measuring each 'processes of change' are displayed in Table 1. In the version used here, participants responded to each item on a five-point Likert scale $(1=$ never; $5=$ repeatedly).

c. Temptation: it is a tool for assessing situational temptation. Three sub-factors were used in this study. This construct contains three items on social situations, negative affect situations, and habitual/ craving situations. The response categories range from 1 (not at all tempted) to 5 (extremely tempted). 
Table 1 Processes of change used in the study

\begin{tabular}{lll}
\hline Sub-factors & Behavioral/experiential process & Item example \\
\hline Counterconditioning & Behavioral & When I am tempted to smoke I think about something else \\
Self-liberation & Behavioral & I tell myself I can quit if I want to \\
Social-liberation & Experiential & I notice that nonsmokers are asserting their rights. \\
Consciousness raising & Experiential & I recall information people have given me on the benefits of quitting smoking \\
Reinforcement management & Behavioral & I am rewarded by others if I don't smoke. \\
Environmental reevaluation & Experiential & I consider the view that smoking can be harmful to my environment \\
Dramatic relief & Experiential & Warnings about the health hazards of smoking move me emotionally \\
Self-reevaluation & Experiential & I get upset when I think about my smoking. \\
Stimulus control & Behavioral & I remove things from my home or place of work that remind me of smoking \\
Helping relationships & Behavioral & I have someone who listens when I need to talk about my smoking \\
\hline
\end{tabular}

d. Decisional balance: it measures smoker's opinion on quitting. This construct contains six items including items on pros and cons. The items employed a five-point Likert-type scale ranging from 1 , (not important) to 5 (extremely important).

\section{Translation}

The TTM Questionnaire was translated from English into Persian by two translators and back translated by two independent translators. The translators were fluent in both English and Persian. They were all experienced health care professionals who have been working for many years. Then, the research team and translators examined the questionnaire for accuracy [15]. To assess the content validity a panel of experts including 10 health professionals (seven specialists in health education and three experts in tobacco control) evaluated the questionnaire for technical issues and wordings. Item allocation and scaling also was checked. Accordingly a few minor changes were made. The face validity of the instrument was assessed by 20 male smokers to insure that they understood questions and had no difficulties in responding to questions [16]. This sample was not included in the main study.

\section{Statistical analysis}

Descriptive statistics were computed for describing the characteristics of the sample. In order to examine the psychometric properties of the questionnaire several statistical tests were applied:

Validity: The confirmatory factor analysis (CFA) was performed in order to test the assumed theoretical framework behind the instrument. Various fit indices were used to asses fit of the model to the data: the goodness of fit index (GFI), the comparative fit index (CFI), the root mean square error of approximation (RMSEA), and the relative chi-square statistic $\left(\mathrm{x}^{2} / \mathrm{df}\right)$. Value of the GFI and the CFI around 0.90 were considered acceptable $[17,18]$. For the RMSEA and the relative chi-square values of $\leq 0.08$ and $\leq 3$ reflected acceptable fit of the model, respectively [18-21].
Reliability: to determine the reliability of the instrument, the internal consistency was tested using the Chronbach's alpha coefficient. We also estimated intraclass correlation coefficient (ICC) in order to assess the stability. Forty smokers from the same sample were randomly selected and responded to the questionnaire twice with a 2-weeks interval. The statistical program SPSS for Windows version 16.0 and LISREL 8.80 was used to carry out the analyses. The P value was set at 0.05 .

\section{Ethics}

The ethics committee of Trabiat Modares University approved the study. Informed consent was obtained from all participants.

Table 2 Demographic characteristics of the study sample $(n=150)$

\begin{tabular}{lll}
\hline & Number & $\%$ \\
\hline Age & & \\
$22-30$ & 38 & 25.3 \\
$31-38$ & 58 & 38.7 \\
$39-46$ & 32 & 21.3 \\
$47-58$ & 22 & 14.7 \\
Mean (SD) & $36.51 \pm 7.94$ & - \\
Marital status & & \\
Single & 23 & 15.3 \\
Married & 127 & 84.7 \\
Education & & \\
$<12$ years & 52 & 34.7 \\
12 years & 66 & $44 / 0$ \\
$>12$ years & 32 & 21.3 \\
Fagerstrom test for nicotine dependence & & \\
$\leq 5$ & 126 & 84.0 \\
$>5$ & 24 & 16.0 \\
\hline
\end{tabular}




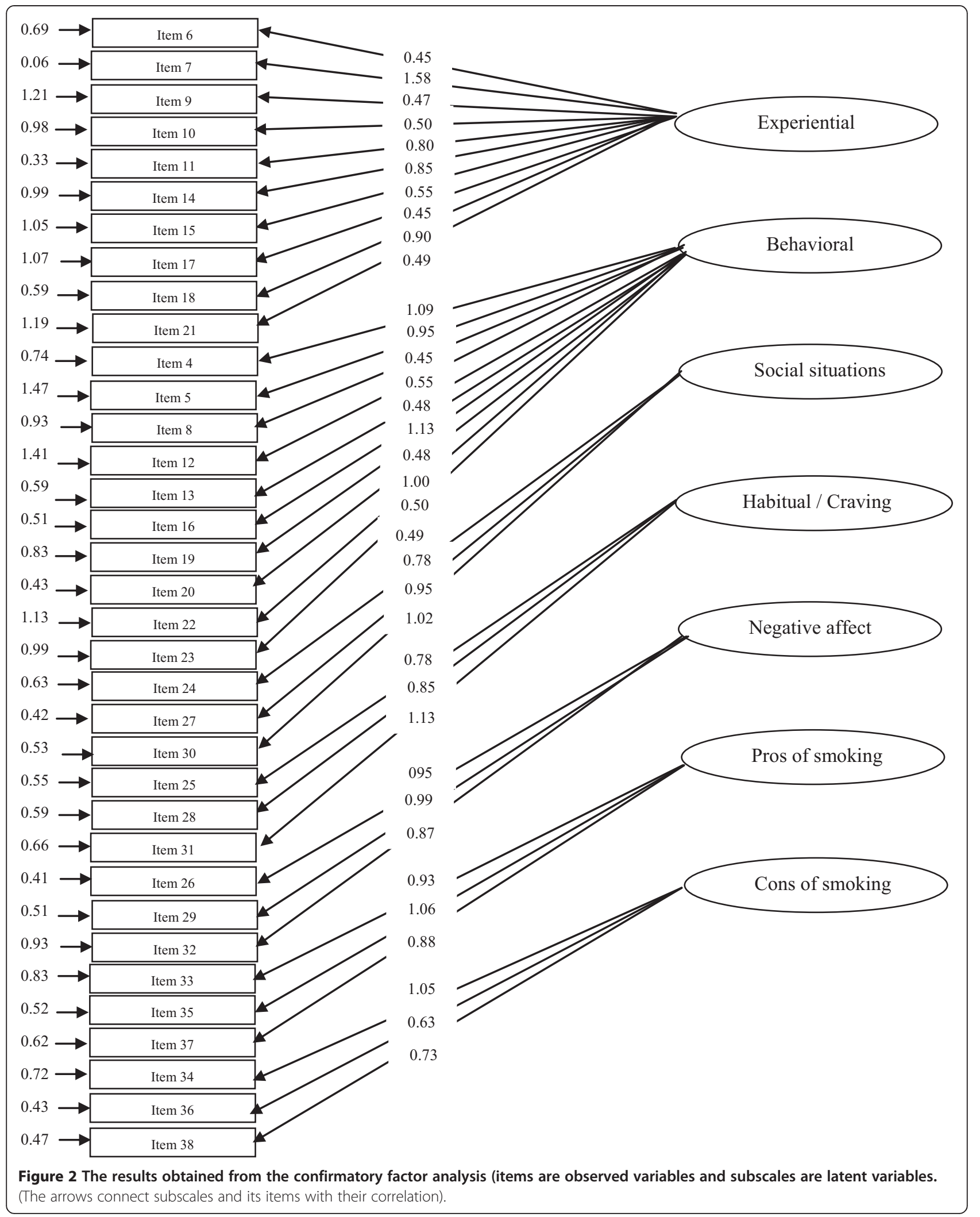




\section{Results}

In all 150 smokers were entered into the study. The mean age of participants was $36.51 \pm 7.94$ years ranging from 22 to 58 . The mean age of initiation of smoking was $19.29 \pm 5.27$ year. The characteristics of the study sample are shown in Table 2.

\section{Validity}

The confirmatory factor analysis was performed and the following fit indices were found: the goodness of fit index $(\mathrm{GFI})=0.92$; the comparative fit index $(\mathrm{CFI})=0.91$; the root mean square error of approximation (RMSEA) = 0.065 (95\% CI $=0.063-0.067)$, and the relative chi-square $\left(x^{2} / \mathrm{df}\right)=1.87, \mathrm{p}<0.001$. The model fitted exactly for the study population. However to improve the model fit, modification indices for the regression weights were examined in order to specify covariances among the indicators or factors. Since a remarkable improvement on fit indexes was not observed, no modifications were made. And thus the model was accepted in its current form. The results are presented in Figure 2.

\section{Reliability}

After the confirmatory factor analysis, the internal consistency of the questionnaire as measured by the Cronbach's alpha was evaluated. Alpha coefficient applied separately for all seven factor ranged between 0.60 and 0.84 , which are accepted value. In addition the stability of the instrument as measured by intraclass correlation of coefficient (ICC) was satisfactory. The results are given in Table 3.

\section{Discussion}

The present study performed a rigorous psychometric evaluation for the translated Iranian version of the short

\begin{tabular}{|c|c|c|c|}
\hline & Number of items & Cronbach's alphas & ICC \\
\hline Processes of change & 20 & 0.79 & 0.70 \\
\hline Behavioral & 10 & 0.72 & 0.77 \\
\hline Experiential & 10 & 0.69 & 0.71 \\
\hline Temptation & 9 & 0.82 & 0.90 \\
\hline Social situations & 3 & 0.75 & 0.78 \\
\hline Habitual/craving & 3 & 0.80 & 0.83 \\
\hline $\begin{array}{l}\text { Negative affect } \\
\text { situations }\end{array}$ & 3 & 0.84 & 0.79 \\
\hline Decisional balance & 6 & 0.60 & 0.71 \\
\hline Pros of smoking & 3 & 0.79 & 0.82 \\
\hline Cons of smoking & 3 & 0.60 & 0.61 \\
\hline Total & 35 & 0.80 & 0.65 \\
\hline
\end{tabular}

Figures in bold are calculated for Process of change, Temptation, Decisional Balance, and for the all items. form TTM Questionnaire for smoking cessation. In general, the result showed that it was a valid instrument for measuring smoking behavior change among Iranians. Developing theory-based instruments are considered an important prerequisite for any attempt to implement and evaluate health education/promotion interventions. Therefore in this context we believe the findings from the current study could be helpful for those who are involved in tobacco control programs both at action level and at research settings.

We performed the confirmatory factory analysis in order to ascertain if the coherence between the data and the theoretical structure exist. The results indicated that the instrument included seven subscales. Of these, two subscales meant to refer to the processes of change [22]. The process of change is a key construct of the TTM and thus merits full consideration when developing instruments for assessing behavior changes. The contribution of such subscales to the process of change implies when developing targeted interventions one should be careful to provide conditions to move target audience from preparation to action stage.

Temptation reflects a psychological state that might encourage an individual to engage in smoking when confronted with a difficult situation. As expected, the nine items of the temptation construct were organized three subscales: 'social situation', 'habitual/craving' and 'negative affect'. This result replicates the structure found in other studies [23-26]. In fact, this model suggests that the three subscales should be considered when designing a tailored intervention for smoking cessation.

As expected, decisional balance revealed two subscales: pros and cons $[23,25,27]$. This result indicates that the instrument was well discriminated benefits and barriers involved in making the decision to quit smoking. Decisional balance of the TTM implies that pros and cons are relatively important part of the model. Perhaps for changing risk behaviors among target populations it is essential to focus on pros and cons for that specific behavior.

The findings indicated that the model from the original inventory produced an acceptable fit to our data [28]. In addition we performed two statistical tests to assure that the instrument was reliable. The Cronbach's alphas coefficient for the instrument indicated that all measures had good internal consistency [29]. Also testretest reliability was carried out as a measure of instrument's stability [30]. The findings were satisfactory lending support for its further reliability.

\section{Limitations}

This study had some limitations. The study participants were male and it is not clear if we included females in the study we would obtain the same results. Furthermore, we recruited smokers who were in the preparation 
stage and thus the reliability and validity of the measure may look different among smokers in other stages. Nevertheless, the findings from this study showed that this instrument could be used for measuring behavior changes in interventions designed for quit smoking among adult male who wish to change his behavior in the next 30 days.

\section{Conclusion}

The current study provided psychometric evidence for an appropriate, reliable, and valid tool to determine smoking behaviors among Iranian adult smokers. This instrument can be utilized for behavior change studies. Indeed, the findings from this study could be applied in designing smoking cessation interventions.

\section{Competing interests}

The authors declare that they have no competing interests.

\section{Authors' contributions}

FS was the main investigator, designed the study, collected the data and wrote the first draft. SN supervised the study. $\mathrm{AH}$ and $\mathrm{EH}$ were the study consultants. AM critically reviewed the paper and provided the final manuscript. All authors read and proved the final draft.

\section{Acknowledgements}

This paper was originated from the first author's PhD thesis at Faculty of Medical Sciences, Tarbiat Modares University. The authors are grateful to all who helped to make this study possible.

\section{Author details}

'Department of Health Education, Faculty of Medical Sciences, Tarbiat Modares University, Jalal Ale Ahmad Highway, P.O. Box: 14115-331, Tehran, Iran. ${ }^{2}$ Department of Biostatistics, Faculty of Medical Sciences, Tarbiat Modares University, Jalal Ale Ahmad Highway, P.O. Box: 14115-331, Tehran, Iran. ${ }^{3}$ Mental Health Research Group, Health Metrics Research Center, Iranian Institute for Health Sciences Research, ACECR, P.O. Box 13185-1488, Tehran, Iran.

Received: 10 June 2013 Accepted: 12 December 2013

Published: 17 December 2013

\section{References}

1. Centers for Disease Control and Prevention (CDC): Best practices for comprehensive tobacco control programs. Atlanta: Department of Health and Human Services, Centers for Disease Control and Prevention; 2007.

2. Glanz K, Rimer BK, Viswanath K: Health behavior and health education: theory, research and practice. 4th edition. San Francisco: Jossey-Bass A Wiley Imprint; 2008.

3. Butler JT: Principles of health education and health promotion. 3rd edition. Belmont, CA: Wadsworth; 2001.

4. Sharma M, Romas JA: Theoretical foundations of health education and health promotion. MA: Jones and Bartlett Publishers; 2008.

5. Prochaska JO, Velicer WF: The transtheoretical model of health behavior change. Am J Health Promot 1997, 12:38-48.

6. Slade P, Laxton-Kane M, Spiby H: Smoking in pregnancy: the role of the transtheoretical model and the mother's attachment to the fetus. Addict Behav 2006, 31:743-757.

7. Lam TH, Chan B, Ho SY, Chan WM: Stage of change for general health promotion action and health-related lifestyle practices in Chinese adults. Prev Med 2004, 38:302-308.

8. Krik A, MacMillan F, Webster N: Application of the transtheoretical model to physical activity in older adults with type 2 diabetes and/or cardiovascular disease. Psychol Sport and Exerc 2010, 11:320-324.

9. Di Noia J, Prochaska JO, Contento IR: Application of the transtheoretical model to fruit and vegetable consumption among economically disadvantaged African-American adolescents: preliminary findings. Am J Health Promot 2006, 20:342-348.
10. Dishman RK, Jackson AS, Bray MS: Validity of processes of change in physical activity among college students in the TIGER study. Ann Behav Med 2010, 40:164-175.

11. Rossi SR, Greene GW, Rossi JS, Plummer BA, Benisovich SV, Benisovich SV, Keller S, Velicer WF, Redding CA, Prochaska JO, Pallonen UE, Meier KS: Validation of decisional balance and situational temptations measures for dietary fat reduction in a large school-based population of adolescents. Eat Behav 2001, 2:1-18.

12. Fava JL, Rossi JS, Velicer WF, Prochaska JO: Structural confirmation of short form instruments for the transtheoretical model. In Paper presented at the 99th Annual Meeting of the American Psychological Association, San Francisco, CA.; 1991.

13. Cancer Prevention Research Center, University of Rhode Island: Measures. http://www.uri.edu/research/cprc/measures.htm\#Smoking.

14. Kim YH: Application of the transtheoretical model to identify psychological constructs influencing exercise behavior: a questionnaire survey. Int I Nurs Stud 2007, 44:936-944.

15. Mapi Linguistic Validation Process. http://www.mapigroup.com/Services/ Linguistic-Validation/PROs-and-ClinROs.

16. Waltz CF, Strickland OL, Lenz ER: Measurement in nursing and health research. 4th edition. New York: Springer Publishing Company; 2010.

17. Kline RB: Principles and practice of structural equation modeling. 3rd edition. New York: Guilford Press; 2010.

18. Hu L, Bentler PM: Cutoff point criteria for fit index in covariance structure analysis: conventional criteria versus new alternative. Struct Equ Modeling 1999, 6:1-55.

19. Browne MW, Cudeck R: Single sample cross-validation indices for covariance structures. Multivariate Behav Res 1989, 24:445-455.

20. MacCallum RC, Browne MW, Sugawara HM: Power analysis and determination of sample size for covariance structure modeling. Psychol Methods 1996, 1:130-149.

21. Munro BH: Statistical methods for health care research. 5th edition. Philadelphia: Lippincott William \& Wilkins co; 2005.

22. Anatchkova MD, Velicer WF, Prochaska JO: Replication of subtypes for smoking cessation within the preparation stage of change. Addict Behave 2006, 31:359-366.

23. Velicer WF, DiClemente CC, Rossi JS, Prochaska JO: Relapse situations and self-efficacy: an integrative model. Addict Behav 1990, 15:271-283.

24. Plummer BA, Velicer WF, Redding CA, Prochaska OJ, Rossi JS, Pallonen UE, Meier KS: Stage of change, decisional balance, and temptations for smoking measurement and validation in large, school-based population of adolescents. Addict Behav 2001, 26:551-571.

25. Yasin SM, Taib KM, Zaki RA: Reliability and construct validity of the Bahasa Malaysia version of transtheoretical model (TTM) questionnaire for smoking cessation and relapse among Malaysian adult. Asian Pacific J Cancer Prev 2011, 12:1439-1443.

26. Fava JL, Velcier WF, Prochaska JO: Applying the transtheoretical model to a representative sample of smokers. Addict Behav 1995, 20:189-203.

27. Velicer WF, Diclemente CC, Prochaska JO, Brandenberg N: A decisional balance measure for assessing and predicting smoking status. J Pers Soc Psychol 1985, 48:1279-1289.

28. Schermelleh-Engel $\mathrm{K}$, Moosbrugger $\mathrm{H}$, Müller $\mathrm{H}$ : Evaluating the fit of structural equation models: tests of significance and descriptive goodness-of-fit measures. Methods Psychol Res Online 2003, 8:23-74.

29. Polit DF, Beck CT: Nursing research principles and methods. 7th edition. Philadelphia: Lippincott Williams \& Wilkins; 2003.

30. Baumgartner TA, Chung H: Confidence limits for class reliability coefficients. Meas Phys Educ Exerc Sci 2001, 5:179-188.

doi:10.1186/1471-2458-13-1186

Cite this article as: Sarbandi et al:: The transtheoretical model (TTM) questionnaire for smoking cessation: psychometric properties of the Iranian version. BMC Public Health 2013 13:1186. 